\title{
ACCESS TO BIOLOGICAL MATERIAL: ISSUES FACING SRI LANKA
}

\author{
JAGATH GUNEWARDANE \\ Attorney at Law, Sri Lanka
}

Proceedings of the South and Central Asian MAB Meeting of Experts on Environmental Conservation, Management and Research, Hikkaduwa, Sri Lanka 15-18 October 2002

The terms "access" and "benefit sharing" came into general usage with the signing of the Convention on Biological Diversity (CBD) in 1992. The three objectives of the CBD are (according to Article 1 - objectives), the conservation of biological diversity, access to genetic resources, and the fair and equitable sharing of benefits arising out of the use of genetic resources. The measures that are needed to facilitate access to genetic resources have been more fully described in Article 15 (Access to genetic resources).

The term "access" is not defined in the CBD under the definitions in Article 2. This means that the word has to be used in the general context. It is the ability to get the required physical material, and the ability to use them as needed by the recipient. The first part of this definition makes the term clear in the manner it is used in the CBD, specifically in relation to Articles 15(1), 15(2), 15(3), 15(4) and 15(5). The other part comes in because it is found that the use of a physical resource may be subjected to certain legal provisions. This is inferred in Articles 15(4), 15(7), and again in Article 16 (Access to and transfer of technology).

The CBD has limited the scope of access and benefit sharing only to genetic resources (Articles 1,15 and 16). The term genetic resources means genetic material of actual and potential value (Article 2). It has left all biological material out of the scope of access and benefit sharing. It is seen that access is sought not only to genetic material, but also to the wider context of biological material.

The associated practical problem is that it is difficult, if not impossible, to isolate the genetic material from the wider biological material in which it is always found, when giving access. This results in the recipient automatically gaining access to a large amount of biological material along with the genetic material, which may after all, not be regulated under the regime of access and benefit sharing. Therefore, it is better to address the issue as "access to biological material", rather than confining it to the "access to genetic resources".

Several factors need to be taken into consideration when looking at the issues involving access. The most important is the rich biological diversity found in Sri Lanka. The rate of endemism is about $25 \%$, making it the highest in southeast Asia. There are 3,368 species of flowering plants, 314 ferns, 192 fungi, 896 algae, 190 
liverworts and 575 species of other lower plants. The fauna is made up of 86 species of mammals, 236 species of resident birds (to which a further 194 migrants, vagrants and seabirds can be added) 177 reptiles, 91 fresh water fishes, among vertebrates, and over 60 land and freshwater crabs, 242 butterflies, 525 beetles and 139 mosquitoes form part of the invertebrate fauna. Sri Lanka is one of the 25 places identified as Biodiversity Hotpots for Conservation Priorities, together with the Western Ghats region of India. The same study ranks these two, as one unit and one of the eight Hottest Hotspots in the world.

Another factor that needs to be given consideration is the widespread traditional use of native biological diversity since ancient times. These uses have created a rich base of Indigenous Knowledge or Traditional Knowledge that deals with identification, sustainable use and methods of use. This knowledge is not static and is continuously updated, modified and added upon on use.

This knowledge is particularly developed in agriculture and in traditional medicinal practices. It is seen that the same material is used for the same purpose in more thar one country in the region and for different purposes in different countries.

The biological diversity of Sri Lanka was viewed since ancient times as something that belongs to everybody and is of common benefit to mankind. Thus, no one laid claim to it or any segment of it as their own. Material and knowledge were freely shared among those who needed it. Living beings, both animals and plants, were not valued in terms of the benefits that they would bring, but in the broader context of inherent value, which simply meant for what they were, and it did not matter whether there were any benefits or none. Animals were left unharmed, owing not to their economic or aesthetic values, but because it was deemed improper to harm other living beings. This view was nurtured in Buddhism, which taught the need to respect and care for all living beings.

This concept is at variance with the widely held concept of utility value. Even the CBD has acknowledged and adopted the utility value of biological material. This is shown by the distinction drawn between biological and genetic material and biological and genetic resources. The CBD defines (Article 2) genetic material, as biological resources and genetic resources. Accordingly, material is deemed a resource when it has some actual or potential value or use to humanity. The definition of biological resources in the CBD does not take into account its contribution to the stability of eco-systems and the maintenance of life-support cycles.

The issues regarding access to biological material and genetic material have two components. One is obtaining the needed material and its export, which deals with the physical component. The other is the legal rights necessary to make use of it, or the intangible component. These two components are covered by different 
legal enactments. The physical material is covered by laws that protect and regulate the use of plants and animals. The rights to use are covered by Intellectual Property Rights (IPR) laws, and through contractual agreements.

The export of any wild animal or part is covered and regulated by the Fauna and Flora Protection Ordinance, No. 02 of 1937 as amended. It applies equally to all native animals, whether being protected or not. The export of an animal or pet (which covers genetic material, secretions, extracts) can be done only under a permit issued by the Department of Wildlife Conservation. The export of any plant that is protected under this enactment needs a similar permit. The granting of permits to export any non-protected plant or parts is done by the Forest Department under the provisions of the Forest Ordinance. In addition, some species of aquatic organisms need a permit under the Fisheries and Aquatic Resources Act. Any export that does not conform to these laws is illegal. These laws have been used quite successfully to control the illegal export or smuggling of biological resources.

It has increasingly been seen that recipients of biological material (both legal and illegal) have a tendency of gaining monopolies over the resources. This is always done to gain exclusive rights over the material, and to prevent others from making use of the same resources. These rights are sometimes held against the rights of the provider country by getting these protected as intellectual property of the recipient. The two IPR systems that are used to gain monopolies are Patent Laws and Plant Breeders Rights Laws (PBR laws).

A patent gives a periodic monopoly to the creator of a useful new innovation in exchange for a full disclosure of the innovation. This disclosure is to ensure that others can make use of the information, and to make the same thing after the period of monopoly expires. In Sri Lanka, it is not possible to patent living things and biological material since they are discoveries (Section 59 (3) of the code of Intellectual Property Act, No. 52 of 1979). Many countries have similar exclusions. However, some developed countries have made it possible to patent discoveries, which include any animals and plants that can be shown to be new, and all components found in these living beings including genetic material.

The Plant Breeders Rights Laws give periodic monopoly rights over new varieties of plants. Sri Lanka does not have such a law, and no one can claim any rights over a plant variety. However, there is a draft of a PBR law, which was presented in July 2001. The enactment of such a law is a requirement under the Trade Related aspects of Intellectual Property Rights (TRIPS) Agreement. (Article 27 (3) (b) of TRIPS). However, this provides for a country to have a unique (Sui generic) Act to suit their own requirements. Some developed countries have PBR laws that make it possible to claim varieties as new, if they differ in one distinct characteristic. 
The claiming of intellectual property rights over plant varieties, traditional lives, folk medicines, compounds that were isolated using traditional uses as a base, genetic material, and even over new organisms, genes and useful products, is a problem faced by many countries rich in bio-diversity. It was found that more than fifty such patents have been obtained in the USA, Japan, Australia, and in the European Patent Office (RPO), and several more registered at the World Intellectual Property Office (WIPO) which infringe and interfere with our rights.

The CBD recognizes the sovereign rights of states over their natural resources. [Article 15(1)]. However, neither Article 15 that deals with access to genetic resources, nor any other article mentions anything about the intellectual property rights over material that had been provided by donor countries. It is neither explicitly stated, nor implied, whether the $\mathrm{CBD}$ accepts or rejects the granting of intellectual property rights to biological and genetic material. There is no provision even to address disputes that may arise from the recipients getting such monopolies against the wishes of a donor country. An argument that can be brought is that since Article $15(4)$ of the CBD states that access shall be on mutually agreed terms, these could also be addressed in such agreements. If this is to be so, then it is an admission of failure on part of the $\mathrm{CBD}$ to protect the rights of donors.

It is therefore seen that countries like Sri Lanka, whose rights are infringed by patents obtained in other countries, have only one option. That is to get these patents revoked or abandoned by resorting to unilateral action on a case by case basis. India succeeded in getting the patent dealing with wound healing properties of turmeric revoked through litigation in USA, and getting many of the claims in the Basmati patent revoked in USA. Sri Lanka was recently successful in getting the two patents in Japan that covered anti-diabetic properties of Kotala Himbutu (Salacia reticulata) to be abandoned. These examples of recent successes can be gainfully analysed to draw necessary inferences to redeem our lost rights. 